\title{
A Study on Audiologist's Perception and Performance Levels for the Evidence-Based Practice
}

\author{
Tae Yang Ji', Soo Jin Cho ${ }^{2}$ \\ 'Kwangwoo Medix Korea, Seoul, Korea \\ ${ }^{2}$ Department of Speech-Language Pathology \& Audiology, Nambu University, Gwangju, Korea
}

청능사의 근거기반실무에 대한 인식 및 실행 수준에 관한 연구

지 태 양 $^{1} \cdot$ 조 수 진 ${ }^{2}$

광우메딕스 ${ }^{1}$, 남부대학교 언어치료청각학과 ${ }^{2}$

\begin{abstract}
Purpose: This study aimed to contribute to improving adaptability of the evidence-based practice (EBP) in the clinical and rehabilitation setting, while considering the audiologist's perception and performance levels of the EBP and the information resources used in the clinical decision-making. Methods: The research conducted a survey on computers or cell phones using the web-based drive provided by Google's search engine. Eighty audiologists (42 men, 38 women) were participated. Results: The findings were as follows: First, the understanding level for the EBP concept was below average by $2.13( \pm 1.18)$ points, and the general perception level for the EBP was average $3.49( \pm 0.53)$ points. Influential factors on the perception for the EBP were in the order of final academic background, experience of papers publication, and use of the web-based database (DB). Second, the performance level of the EBP was average by $3.03( \pm 0.76)$ points, and the influential factors on the performance level for the EBP were in the order of final academic background, use of the webbased DB, and membership of academy and conference participation. Third, according to the analysis on the multiple responses to the information resources used in the clinical decision-making, the responses were in the order of colleague's advice (18.0\%), text books (16.7\%), and my own clinical experience (13.1\%). Conclusion: This study concluded that the audiologists positively recognized the EBP and the performance level for the EBP was less than the perception level. It is necessary to preferentially provide the opportunities of education experience on the EBP and continuously provide education on the EBP application methods.
\end{abstract}

Key Words: Audiologist, Evidence-based practice, Information resources use.

Received: September 27, 2016 / Revised: October 10, 2016 / Accepted: October 11, 2016

Correspondence: Soo Jin Cho, Department of Speech-Language Pathology \& Audiology, Nambu University, 23 Cheomdanjungang-ro, Gwangsan-gu, Gwangju 62271, Korea

Tel: +82-62-970-0215 / Fax: +82-504-390-7434 / E-mail: sj2434@nambu.ac.kr

\section{INTRODUCTION}

근거기반실무(evidence-based practice, EBP)는 개별 환자 를 치료하고 돌보기 위한 서비스를 제공하고 임상적 의사결정 을 내릴 때, 그 시점에서 취할 수 있는 가장 최선의 근거를 신중 하고 명백히 그리고 현명하게 사용하는 과정을 의미한다(Sackett et al., 1996). 역사적으로 $\mathrm{EBP}$ 는 1990년대 의학 분야에서 대 두되어 근거기반의학(evidence-based medicine)으로 정립된 후 간호, 보건, 사회복지, 재활, 상담 등 다양한 전문분야로 확 대되면서 체계화되었으며, 개인의 임상적 전문성(clinical experience)과 체계적인 연구에서 도출된 가능한 최선의 연구 근 거(best research evidence)를 환자의 가치(관)(patient values) 과 기대를 함께 고려하여 치료나 중재의 결과를 향상시키는 데 그 목적을 두고 있다(Cho, 2006). EBP 실행 과정은 크게 5단계 로 나눌 수 있는데(Cook et al., 1992), 첫 번째 단계는 임상 질 문하기로 임상 현장에서 발생할 수 있는 의문점이나 제기된 문 제에 답할 수 있는 명확한 질문의 형태로 만드는 과정이다. 그 리고 질문에는 반드시 환자, 대상 또는 문제(patient, population or problem), 치료법(intervention or index test), 비교할 수 있는 치료법(comparison, comparator or control), 및 예상 되는 결과(outcome) 등의 요소가 포함되어야 한다. 두 번째 단 계는 임상 질문에 답할 수 있는 최선의 근거를 찾기 위해서 다 
양한 분야의 전문 데이터베이스(database, $\mathrm{DB}$ )를 검색해야 한 다. 세 번째 단계에서는 근거의 타당성, 임상적 관련성 및 적용 가능성 등을 비판적으로 분석하고 네 번째 단계에서 과학적 연 구에서 얻은 최선의 근거를 임상 실무에 적용한 후, 다섯 번째 단계에서 $\mathrm{EBP}$ 실행 과정의 결과를 평가하게 된다(Cho, 2014; Zipoli \& Kennedy, 2005).

국내에서는 보건복지부와 건강보험심사평가원을 중심으로 정책적 의사결정과정에서 $\mathrm{EBP}$ 가 강조되고 있으며, 임상적 의 사결정을 할 때 체계적이고 과학적인 방법으로 연구 근거를 찾 아 평가한 후, 임상 실무에 적용하도록 권고하고 있다(Lee, 2001; Park, 2012). 특히 간호, 작업치료 및 언어치료 등 의료보 건 전문분야에서 $\mathrm{EBP}$ 에 대한 중요성, 인식 및 활용태도 등에 대한 연구가 다양하게 진행되어 왔으며(Choi \& Hwang, 2015; Kang et al., 2007; Lee, 2012; Yoon et al., 2014), EBP 실행 과 정을 통한 임상적 판단이 환자에게 유용하다는 결론을 얻고 있다. 한편 2005년 미국언어청각임상협회(American SpeechLanguage Hearing Association, ASHA)에서도 청능사와 언어 치료사들이 임상적 의사결정을 내릴 때 $\mathrm{EBP}$ 개념에 근거해야 한다는 내용을 공식 정책안으로 문서화하였다(ASHA, 2005a). 즉 서비스 대상자의 관심, 가치 요구 및 선택을 반영하는 고품 질의 임상적 서비스를 세공하기 위해서는 외부의 과학적 증거, 임상적 전문지식 및 내담자/환자/보호자의 의견이나 관점이 통 합된 $\mathrm{EBP}$ 원리를 적용해야 한다고 권고하였다. 또한 임상가, 연구자, 환자 및 보호자들에게 $\mathrm{EBP}$ 결정 과정에 필요한 권고 사항이나 관련 자료들을 청각 및 의사소통장애관련 질환을 중 심으로 'ASHA Evidence Maps'으로 정리해서 제공하고 있다 (ASHA, 2005b; Choi \& Hwang, 2015). 이와 관련하여 청각분 야에서도 $\mathrm{EBP}$ 에 대한 중요성을 인식하고 보청기와 인공와우 를 포함한 증폭기기(Cox, 2005; Leigh et al., 2011)와 청각장애 성인을 위한 청능재활(Hickson et al., 2013) 분야에서 EBP 원 리를 임상에서 적용한 사례를 포함한 다양한 $\mathrm{EBP}$ 관련 연구 들을 진행해 왔다.

이와 같은 $\mathrm{EBP}$ 의 중요성에 대한 인식에도 불구하고 과중한 업무 부담으로 인해 $\mathrm{EBP}$ 를 실행할 시간의 부족, 연구논문에 대한 검색 능력의 부족, 연구논문에 대한 비평능력의 부족, 연 구결과 보다는 임상가 개인의 경험 중시 등과 같은 방해 요인들 로 인해서 $\mathrm{EBP}$ 를 실제 임상 현장에 적용하기에는 한계가 있으 며, $\mathrm{EBP}$ 인식에 대한 변화가 필요한 것으로 나타났다(Dysart \& Tomlin, 2002; Kang et al., 2007; Thompson et al., 2006). 또한 $\mathrm{EBP}$ 를 근거로 한 결과는 서비스 대상자 개개인에게 적용 해서 도출한 것이 아니라, 서비스 대상자 그룹에 적용되어 도출 한 개념이기 때문에 개개인의 특성을 고려해서 해석해야 하므 로 주의가 필요하다(Park, 2008).
최근 $\mathrm{EBP}$ 에 근거한 임상적 판단이 보건의료 분야뿐만 아니 라 사회복지, 상담 및 교육 등의 분야에서 점차 그 중요성이 증 대되고 있는 가운데, 타 분야와 비교해 볼 때 국내 청각분야에 서 $\mathrm{EBP}$ 에 대한 인식 및 실행 수준에 대한 논의와 실증적 연구 가 미흡한 것이 현실이다. 이에 본 연구에서는 청능사들을 대상 으로 $\mathrm{EBP}$ 에 대한 인식과 실행 수준 및 임상적 의사결정 시 이 용하는 정보자원을 고찰해 봄으로써 추후 청각분야에서 $\mathrm{EBP}$ 에 대한 인식 변화를 유도하여 임상 및 재활 현장에서의 적용 가능성을 높이는 데 기여하고자 하였다. 구체적인 연구문제는 다음과 같다.

첫째, 청능사의 $\mathrm{EBP}$ 인식 및 실행 수준은 어느 정도이며, 연 구 대상자의 특성에 따라 $\mathrm{EBP}$ 인식 및 실행 수준에 차이를 보 이는가?

둘째, 청능사 $\mathrm{EBP}$ 인식 및 실행 수준에 영향을 미치는 유의 한 요인은 무엇인가?

셋째, 임상적 의사결정 시 이용하는 정보자원에 대한 청능사 의 다중응답 분석 결과는 어떠한가?

\section{MATERIALS AND METHODS}

\section{연구 대상}

2014년 9월부터 2015년 10월까지 전국에 위치하고 있는 개인 및 종합병원, 청각기기 회사, 개인청각센터, 대학 및 연구기관, 기타(특수학교, 복지기관 등)의 청각분야에서 근무하고 있는 청능사들을 대상으로 전화와 SNS를 통해 설문의 목적과 내용 을 설명하고, 이에 동의한 대상자에게만 구글 검색 엔진에서 제 공하는 웹 기반 드라이브를 이용한 설문 문항을 이메일이나 핸 드폰으로 전송한 후 회신한 80명(남자 42명, 여자 38명)을 연구 대상에 포함시켰다. 또한 설문 조사에 동의하였더라도 변심하 거나 기타 다른 이유로 설문조사에 응할 수 없는 경우에는 회 신하지 않아도 된다고 공지함으로써 설문조사를 거절할 수 있 도록 하였다.

연구에 참여한 대상자의 평균연령은 30.27 세 $( \pm 7.19)$ 였으며, 전체 대상자 중 54명(67.5\%)이 학사 출신이었고, 청능사로서의 근무경력은 1년 이상 3년 미만이 32명(40.0\%)으로 가장 많았 으며 전체 대상자의 $76.3 \%$ 가 5년 미만의 근무경력을 소유한 것 으로 나타났다. 근무기관의 경우 개인 및 종합병원에 근무하는 대상자가 26명(32.6\%)으로 가장 많았으며, 개인청각센터와 청 각기기 회사에서 근무하는 청능사가 각각 21명(26.3\%)과 19명 (23.8\%)이었다. 그 외 연구 대상자의 57명(71.3\%)이 현재 청각 학과 관련된 학회나 학술단체의 회원으로 활동하고 있었고, 최 근 2년간 청각학 관련 학술대회에 참석한 적이 있다고 응답한 사람도 59명(73.8\%)에 달했으며, 24명(30.0\%)의 응답자들은 지 
난 6 개월 동안 읽은 평균 논문의 수가 1 편 미만이라고 대답하 였다. 웹 기반 데이터베이스 활용 정도를 묻는 문항에서는 53 명 (66.3\%)이 1년에 몇 번 사용하거나 활용하지 않는다고 대답하

Table 1. Participant characteristics

\begin{tabular}{|c|c|}
\hline Characteristics & $\mathrm{n}(\%)$ \\
\hline \multicolumn{2}{|l|}{ Gender } \\
\hline Male & $42(52.5)$ \\
\hline Female & $38(47.5)$ \\
\hline \multicolumn{2}{|l|}{ Age } \\
\hline Twenties & $48(60.0)$ \\
\hline Thirties & $22(27.5)$ \\
\hline Forties & $6(7.5)$ \\
\hline Over fifties & $4(5.0)$ \\
\hline \multicolumn{2}{|l|}{ Final academic background } \\
\hline Associate's degree & $4(5.0)$ \\
\hline Bachelor'degree & $50(62.5)$ \\
\hline Master's degree & $18(22.5)$ \\
\hline Doctor's degree & $8(10.0)$ \\
\hline \multicolumn{2}{|l|}{ Work career } \\
\hline Under one year & $11(13.8)$ \\
\hline One year-three years & $32(40.0)$ \\
\hline Three years-five years & $18(22.5)$ \\
\hline Five years - ten years & $7(8.8)$ \\
\hline \multicolumn{2}{|l|}{ Over ten years } \\
\hline Primary work setting & $12(15.0)$ \\
\hline Private \& general hospital & $26(32.6)$ \\
\hline Hearing device company & $19(23.8)$ \\
\hline Private hearing center & $21(26.3)$ \\
\hline University \& Research Institution & $4(5.0)$ \\
\hline Others & $10(12.5)$ \\
\hline \multicolumn{2}{|l|}{ Membership of academy } \\
\hline Yes & $57(71.3)$ \\
\hline No & $23(28.8)$ \\
\hline \multicolumn{2}{|c|}{ Participation in conference in the recent 2 years } \\
\hline Yes & $59(73.8)$ \\
\hline No & $21(26.3)$ \\
\hline \multicolumn{2}{|l|}{ Paper publication } \\
\hline Yes & $28(35.0)$ \\
\hline No & $52(65.0)$ \\
\hline \multicolumn{2}{|c|}{ Number of reading research papers in the past 6 months } \\
\hline Under 1 & $24(30.0)$ \\
\hline 1 & $12(15.0)$ \\
\hline $2-3$ & $18(22.5)$ \\
\hline $4-5$ & $4(5.0)$ \\
\hline Over 6 & $22(27.5)$ \\
\hline \multicolumn{2}{|l|}{ Use of the web-based DB } \\
\hline Not using & $24(30.0)$ \\
\hline Several times a year & $29(36.3)$ \\
\hline Once a month & $16(20.0)$ \\
\hline Once a week & $7(8.8)$ \\
\hline Everyday & $4(5.0)$ \\
\hline
\end{tabular}

였다. 전체 연구 대상자들의 일반적인 특성은 Table 1 과 같다.

\section{연구 방법}

본 연구에 사용한 설문지는 Choi \& Hwang(2015), Kang et al.(2007), Yoon et al.(2014) 및 Zipoli \& Kennedy(2005)의 선 행연구를 기초로 본 연구에 맞게 수정 및 보완하여 사용하였 다. 설문지는 대상자들의 일반적 특성(10문항), $\mathrm{EBP}$ 에 대한 인 식 수준(9문항), 실행 수준(7문항) 및 임상적 의사결정 시 이용 하는 정보자원에 대한 다중응답(1문항) 등 총 27문항이었다. 이 중 $\mathrm{EBP}$ 에 대한 인식 및 실행 수준에 대한 설문 문항은 Likert 5점 척도를 사용하였으며, 특히 $\mathrm{EBP}$ 에 대한 인식 수준의 2개 문항은 역문항에 해당되어 통계분석 과정에서 역변환한 후 처 리하였다.

설문지의 내용 타당도를 위해 청각학 전공 박사 2 명이 수정 및 보완 작업을 진행하였으며, 26명을 대상으로 예비조사를 실 시한 후 내용을 수정하고 불필요한 문항은 삭제하여 최종 문 항을 완성하였다. 신뢰도 분석을 위해 크론바흐 알파값(Cronbach's $\alpha$ )으로 내적 일관성을 측정한 결과, $\mathrm{EBP}$ 에 대한 인식 수준 요인의 신뢰도 계수는 $0.848, \mathrm{EBP}$ 에 대한 실행 수준 요인 의 신뢰도 계수는 0.783 으로 나타났다.

\section{자료 분석}

수집된 자료는 SPSS (Ver. 18.0, IBM Co., Chicago, IL, USA) 프로그램을 사용하여 연구 도구의 신뢰도 검증을 위해 크론바흐 알파값을 산출하였으며 연구 대상자의 인구통계학적 요인에 대해 빈도 분석을 실시하였고, $\mathrm{EBP}$ 에 대한 인식과 실행 수준의 각 항목별 경향성을 분석하기 위해 연구 목적에 따라 빈도와 백분율, 평균과 표준편차를 산출하였다. 그리고 연구 대상자의 일반적 특성(연령대, 최종학력, 근무경력, 근무기관, 최근 2년간 학술대회 참석 여부, 논문발표 경험 여부, 최근 6개 월 동안 읽은 평균 논문 수, 국내·외 웹 기반 데이터베이스 활 용 정도, $\mathrm{EBP}$ 교육경험)에 따라 $\mathrm{EBP}$ 에 대한 인식과 실행 수준 에서 차이가 있는지를 검증하기 위해서 Mann-Whitney U 검 증과 Kruskal-Wallis $\mathrm{H}$ 검증을 실시하였다. 또한 청능사의 $\mathrm{EBP}$ 인식 및 실행 수준에 영향을 미치는 요인을 알아보기 위 하여 단계별 다중선형 회귀분석(stepwise multiple linear regression analysis)을 실시하였다. 마지막으로 청능사들이 임상 적 의사결정 시 이용하는 정보자원을 알아보기 위한 다중응답 문항에 대한 자료 분석은 빈도분석과 연구 대상자의 성별, 연 령대, 최종학력, 근무경력 및 근무기관의 유형에 따라 교차분 석을 이용하였다. 


\section{RESULTS}

\section{EBP에 대한 인식 및 실행 수준}

\section{$\mathrm{EBP}$ 에 대한 인식 및 실행 수준정도}

$\mathrm{EBP}$ 에 대한 청능사의 인식수준은 $\mathrm{EBP}$ 에 대한 개념 이해정 도와 일반적인 인식 수준을 알아보기 위한 문항으로 구성하였 는데, 우선 $\mathrm{EBP}$ 개념 이해정도는 평균 2.13( \pm 1.18$)$ 점으로 보통 이하의 수준으로 나타났다. 그리고 $\mathrm{EBP}$ 에 대한 일반적인 인식 수준은 평균 3.49( \pm 0.53$)$ 점으로 응답자들의 $\mathrm{EBP}$ 에 대한 일반 적인 인식은 보통 이상으로 나타났다. 문항별로는 '청각학 분야 의 연구동향을 파악하는 것은 청능사로서의 중요한 직업적 책 임이다라는 문항이 4.04 $( \pm 0.83)$ 점으로 가장 높게 나타났으며, 이에 비하여 ' $\mathrm{EBP}$ 는 임상현장에서 과학적 근거가 아닌 요소를 제거할 수 있다' 문항에서는 2.99( \pm 0.82$)$ 점으로 가장 낮았다. 그 외 $\mathrm{EBP}$ 에 대한 인식 수준을 알아보기 위한 설문 문항과 평 균(표준편차)을 Table 2에 제시하였으며, Appendix에서는 전 체 설문 문항을 제시하였다.

청능사의 $\mathrm{EBP}$ 실행 수준을 알아보기 위하여 Likert 5점 척 도로 구성된 7개 전체 문항의 평균 점수를 산출한 결과, 평균 3.03( \pm 0.76$)$ 점으로 보통 정도로 나타나 $\mathrm{EBP}$ 에 대한 인식 수준 에 비해서는 다소 낮게 측정되었다. 문항별로는 '나는 정보검 색, 색인사용, 다운로드, 문서작성 등 컴퓨터를 잘 활용할 수 있
다라는 문항이 3.46( \pm 1.01$)$ 점으로 가장 높았던 반면에 '나는 근무 시간 중 $\mathrm{EBP}$ 에 참여할 시간이 있다'라는 문항이 2.75( \pm 1.03)점으로 가장 낮게 나타났다. 또한 "나는 연구 관련 전문용 어나 통계적 처리방법에 대해서 잘 알고 있다'와 '내가 속한 기 관에서 시행하는 연구(예를 들어 연구모임, 사례발표, 원서강독 등)에 참여하고 있다'라는 문항이 각각 2.88( \pm 0.86$)$ 점과 2.89( \pm 1.24 )점으로 다른 문항에 비해 비교적 낮게 측정되었다. 그 외 $\mathrm{EBP}$ 에 대한 실행 수준을 알아보기 위한 설문 문항과 평 균(표준편차)은 Table 3에 제시하였다.

\section{$\mathrm{EBP}$ 에 대한 인식 및 실행 수준차이}

연구 대상자의 일반적 특성에 따른 $\mathrm{EBP}$ 에 대한 인식 차이를 분석한 결과 연령대 $\left[\chi^{2}=10.812, p=0.013\right]$, 최종학력 $\left[\chi^{2}=\right.$ 42.084, $p=0.000]$, 근무경력 $\left[\chi^{2}=26.425, p=0.000\right]$, 최근 2년 간 학술대회 참석 여부 $[\mathrm{U}=34,975.5, p=0.016]$, 최근 6개월 동 안 읽은 평균 논문 수 $\left[\chi^{2}=24,889, p=0.000\right]$ 및 웹 기반 $\mathrm{DB}$ 활용 정도 $\left[\chi^{2}=22.162, p=0.000\right]$ 에 따라 통계학적으로 유의미 한 차이가 있는 것으로 나타났다 $(p<0.05)$. 반면에 근무기관, 학회 회원 여부, 논문발표 경험 여부 및 $\mathrm{EBP}$ 교육경험 여부에 따른 청능사들의 $\mathrm{EBP}$ 인식에는 차이가 없었다.

또한 연구 대상자의 일반적 특성에 따른 $\mathrm{EBP}$ 실행 수준은 근무기관, 학회 회원 여부 및 $\mathrm{EBP}$ 교육 경험 여부를 제외한 연 령대 $\left[\chi^{2}=13.903, p=0.003\right]$, 최종학력 $\left[\chi^{2}=93.718, p=0.000\right]$, 근

Table 2. Question items and means (SD) for the perception level for the EBP

\begin{tabular}{ll}
\hline \multicolumn{1}{c}{ Question $(9$ items $)$} & Mean $( \pm \mathrm{SD})$ \\
\hline 1. How much do you know about the concept of the EBP? & $2.13( \pm 1.18)$ \\
2. I think that the EBP is important in the clinical hearing field. & $3.66( \pm 0.93)$ \\
3. The EBP can remove the factors that are not scientific basis in the clinical setting. & $3.99( \pm 0.82)$ \\
4. The EBP can improve auditory arbitration or the rehabilitation effects. & $3.64( \pm 0.82)$ \\
5. The EBP should be applied in the clinical decision-making. & $3.58( \pm 0.90)$ \\
6. While the EBP is ideal, it is not easy to be daily applied in the clinical setting. & $3.54( \pm 0.91)$ \\
7. Identifying the research trends in the audiology field is an important professional responsibility as an audiologist. & $4.04( \pm 0.83)$ \\
8. Since there are lacking research results on audiology, the use of the EBP is limited. & $3.64( \pm 0.86)$ \\
9. If there are special lectures or courses on the EBP, I am willing to attend the lectures. & $3.64( \pm 0.90)$
\end{tabular}

EBP: evidence-based practice, SD: standard deviations

Table 3. Question items and means (SD) for the performance level for the EBP

\begin{tabular}{lc}
\hline \multicolumn{1}{c}{ Question $(7$ items $)$} & Mean $( \pm$ SD) \\
\hline 1. I can well use computers including information search, index use, download and document writing for the EBP. & $3.46( \pm 1.01)$ \\
2. I am well aware of the database that can search the research papers and research results. & $3.10( \pm 1.06)$ \\
3. I am well aware of the research-related technical terms or statistical processing methods. & $2.88( \pm 0.86)$ \\
4. I can read, interpret and evaluate the domestic and international research papers. & $3.05( \pm 0.97)$ \\
5. I solve the problems by referring the research results or literature in the current clinical setting. & $3.09( \pm 1.12)$ \\
6. I am participating in the research meetings held by the agency where I work. & $2.89( \pm 1.24)$ \\
7. I have time to participate in the EBP during working hours. & $2.75( \pm 1.03)$ \\
\hline
\end{tabular}

EBP: evidence-based practice, SD: standard deviations 
Table 4. Differences of perception and performance levels for the EBP according to participant characteristics

\begin{tabular}{|c|c|c|c|c|}
\hline \multirow{2}{*}{ Characteristics } & \multicolumn{2}{|c|}{ Mean (SD) } & \multicolumn{2}{|c|}{$\chi^{2} / U$} \\
\hline & EBP perception & EBP performance & EBP perception & EBP performance \\
\hline Age & & & $10.812^{*}$ & $13.903^{\dagger}$ \\
\hline Twenties & $3.57(0.83)$ & $2.89(1.04)$ & & \\
\hline Thirties & $3.57(0.90)$ & $3.23(1.04)$ & & \\
\hline Forties & $3.56(1.47)$ & $3.33(1.36)$ & & \\
\hline Over fifties & $4.03(0.69)$ & $3.14(0.65)$ & & \\
\hline Final academic background & & & $42.084^{*}$ & $93.718^{*}$ \\
\hline Associate's degree & $2.94(1.24)$ & $2.50(1.32)$ & & \\
\hline Bachelor'degree & $3.51(0.77)$ & $2.86(0.95)$ & & \\
\hline Master's degree & $3.76(0.94)$ & $3.03(0.98)$ & & \\
\hline Doctor's degree & $4.06(1.14)$ & $4.36(0.77)$ & & \\
\hline Work career & & & $26.425^{*}$ & $47.376^{\ddagger}$ \\
\hline Under one year & $3.53(1.07)$ & $2.60(1.04)$ & & \\
\hline One year-three years & $3.50(0.86)$ & $3.00(1.09)$ & & \\
\hline Three years-five years & $3.56(0.81)$ & $2.98(0.93)$ & & \\
\hline Five years - ten years & $3.50(0.83)$ & $2.82(0.81)$ & & \\
\hline Over ten years & $3.98(0.96)$ & $3.73(1.06)$ & & \\
\hline Primary working setting & & & 6.176 & 2.151 \\
\hline Private \& General Hospital & $3.63(0.98)$ & $3.02(1.13)$ & & \\
\hline Hearing device company & $3.53(0.91)$ & $3.05(1.07)$ & & \\
\hline Private hearing center & $3.68(0.93)$ & $3.17(1.09)$ & & \\
\hline University \& Research Institution & $3.41(0.67)$ & $3.11(0.57)$ & & \\
\hline Others & $3.48(0.69)$ & $2.69(0.88)$ & & \\
\hline Membership of academy & & & $39,750.5$ & $31,238.0$ \\
\hline Yes & $3.61(0.94)$ & $3.02(1.10)$ & & \\
\hline No & $3.54(0.83)$ & $3.06(0.97)$ & & \\
\hline Participation in conference in the recent 2 years & & & $34,975.5^{*}$ & $22,545.5^{\ddagger}$ \\
\hline Yes & $3.64(0.88)$ & $3.16(1.06)$ & & \\
\hline No & $3.43(0.98)$ & $2.66(0.98)$ & & \\
\hline Papers publication & & & $42,496.5$ & $24,635.0^{\ddagger}$ \\
\hline Yes & $3.66(1.03)$ & $3.40(1.11)$ & & \\
\hline No & $3.55(0.83)$ & $2.83(0.98)$ & & \\
\hline Number of reading research papers in the past 6 months & & & $24.889^{\ddagger}$ & $27.951^{\ddagger}$ \\
\hline Under 1 & $3.40(0.90)$ & $2.57(0.92)$ & & \\
\hline 1 & $3.52(0.75)$ & $3.05(1.02)$ & & \\
\hline $2-3$ & $3.65(0.88)$ & $2.95(1.00)$ & & \\
\hline $4-5$ & $4.13(0.75)$ & $3.32(0.77)$ & & \\
\hline Over 6 & $3.68(0.99)$ & $3.53(1.10)$ & & \\
\hline Use of the web-based DB & & & $22.162^{*}$ & $73.819^{\ddagger}$ \\
\hline Not using & $3.39(0.87)$ & $2.70(1.05)$ & & \\
\hline Several times a year & $3.63(0.84)$ & $2.82(0.94)$ & & \\
\hline Once a month & $3.77(1.00)$ & $3.40(0.96)$ & & \\
\hline Once a week & $3.54(0.83)$ & $3.71(1.04)$ & & \\
\hline Everyday & $3.94(1.01)$ & $3.89(0.92)$ & & \\
\hline EBP education experience & & & $31,397.0$ & $23,414.0$ \\
\hline Yes & $3.66(1.03)$ & $3.18(1.20)$ & & \\
\hline No & $3.57(0.87)$ & $2.99(1.02)$ & & \\
\hline
\end{tabular}

${ }^{*} p<0.05,{ }^{\dagger} p<0.01{ }^{\ddagger} p<0.001$. EBP: evidence-based practice, SD: standard deviation 
무경력 $\left[\chi^{2}=47.376, p=0.000\right]$, 최근 2 년간 학술대회 참석 여부 $[\mathrm{U}=22,545.5, p=0.000]$, 논문 발표 경험 여부 $[\mathrm{U}=24,635.0, p=$ 0.000], 최근 6개월 동안 읽은 평균 논문 수 $\left[\chi^{2}=27.951, p=0.000\right]$ 및 웹 기반 데이터베이스 활용 정도 $\left[\chi^{2}=73.819, p=0.000\right]$ 에 따 라 통계학적으로 유의미한 차이가 있는 것으로 나타났다 $(p<$ 0.05). 자세한 내용은 Table 4에 제시하였다.

\section{$\mathrm{EBP}$ 에 대한 인식 및 실행 수준에 영향을 주는 요인}

청능사의 $\mathrm{EBP}$ 인식에 영향을 주는 요인을 예측하기 위하여 연령, 최종학력, 근무경력, 근무기관, 학회 회원 여부, 최근 2년 간 학술대회 참석 여부, 논문발표 경험 여부, 웹 기반 $\mathrm{DB}$ 활용 정도 및 $\mathrm{EBP}$ 교육경험 여부를 독립변수로 하고 청능사의 $\mathrm{EBP}$ 인식을 종속변수로 설정한 후, 단계별 다중선형 회귀분석을 실 시하였다. 그 결과 회귀모형의 적합도인 $\mathrm{F}$ 값이 5.871로 유의한 것으로 나타났으며 $(p<0.05)$, 표준화 계수를 통하여 청능사의 $\mathrm{EBP}$ 인식에 영향을 많이 미치는 요인을 확인해 본 결과, 최종 학력(0.301), 논문발표 경험 여부(0.161), 웹 기반 DB 활용 정도 (0.105) 순으로 나타났다. 즉 학력이 높고 논문발표 경험 및 웹 기반 $\mathrm{DB}$ 활용 정도가 높을수록 $\mathrm{EBP}$ 에 대한 인식 수준이 높을 것으로 추정되지만, 결정계수가 0.076 으로 그 예측력은 매우 낮 게 나타났다(Table 5).

청능사의 $\mathrm{EBP}$ 실행 수준에 영향을 주는 요인을 예측하기 위 하여 $\mathrm{EBP}$ 인식 수준과 마찬가지로 단계별 다중선형 회귀분석 을 실시한 결과, 회귀모형의 적합도인 F값이 4.568로 유의했지 만 $(p<0.05)$, 결정계수가 0.236 으로 청능사의 $\mathrm{EBP}$ 인식 수준과 마찬가지로 예측력이 낮게 나타났다. 청능사의 EBP 실행 수준 에 영향을 많이 미치는 요인을 확인해 본 결과, 최종학력(0.212),
웹 기반 $\mathrm{DB}$ 활용 정도(0.264), 학회 회원 여부(0.194), 학회 참석 여부(-0.133), 근무경력(0.142), 근무기관(-0.081) 순으로 나타났 다(Table 6).

\section{임상적 의사결정 시 이용하는 정보자원}

임상적 의사결정 시 의문점이나 문제해결을 위해서 이용하는 정보자원에 대한 다중응답을 빈도 분석한 결과, 전공 선후배들 이나 동료의 조언이 40 명(18.1\%)으로 가장 많았으며 그 다음이 전공 관련 서적(37명, $16.7 \%)$ 과 자신의 임상적 경험(29명, $13.1 \%)$

Table 5. Multiple regression analysis of the factors affecting the EBP perception level

\begin{tabular}{lcccc}
\hline \multicolumn{1}{c}{ Predictor } & EBP & SE & $\beta$ & $t$ \\
\hline Final academic background & 0.374 & 0.057 & 0.301 & $6.528^{*}$ \\
Papers publication & 0.307 & 0.093 & 0.161 & $3.321^{\dagger}$ \\
Use of the web-based DB & 0.085 & 0.035 & 0.105 & $2.423^{*}$
\end{tabular}

Adjust $\mathrm{R}^{2}=0.076, \mathrm{~F}=5.871^{*}$

${ }^{*} p<0.05,{ }^{\dagger} p<0.01,{ }^{\ddagger} p<0.001$. EBP: evidence-based practice, SE: standard error

Table 6. Multiple regression of the factors affecting the EBP performance level

\begin{tabular}{lcccc}
\hline \multicolumn{1}{c}{ Predictor } & EBP & \multicolumn{1}{c}{ SE } & \multicolumn{1}{c}{$\beta$} & $t$ \\
\hline Final academic background & 0.307 & 0.071 & 0.212 & $4.326^{\ddagger}$ \\
Use of the web-based DB & 0.251 & 0.040 & 0.264 & $6.347^{\ddagger}$ \\
Membership of academy & 0.454 & 0.095 & 0.194 & $4.773^{\ddagger}$ \\
Participation in conference & -0.321 & 0.097 & -0.133 & $-3.308^{\dagger}$ \\
Work career & 0.121 & 0.40 & 0.142 & $3.037^{\dagger}$ \\
Primary work setting & -0.065 & 0.031 & -0.081 & $-2.137^{*}$
\end{tabular}

Adjust $\mathrm{R}^{2}=0.236, \mathrm{~F}=4.568^{*}$

${ }^{*} p<0.05,{ }^{\dagger} p<0.01,{ }^{\ddagger} p<0.001$. EBP: evidence-based practice, $\mathrm{SE}$ : standard error

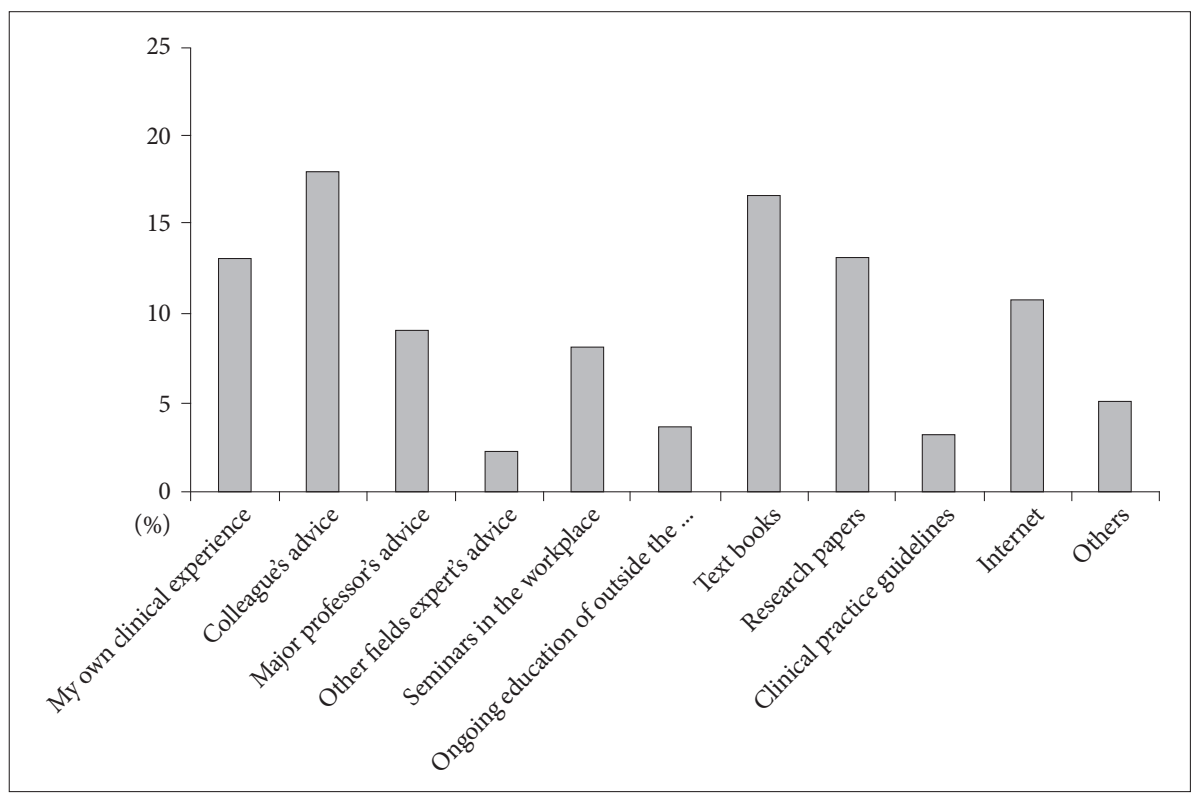

Figure 1. Multiple responses to the information resources used in the clinical decisions-making. 


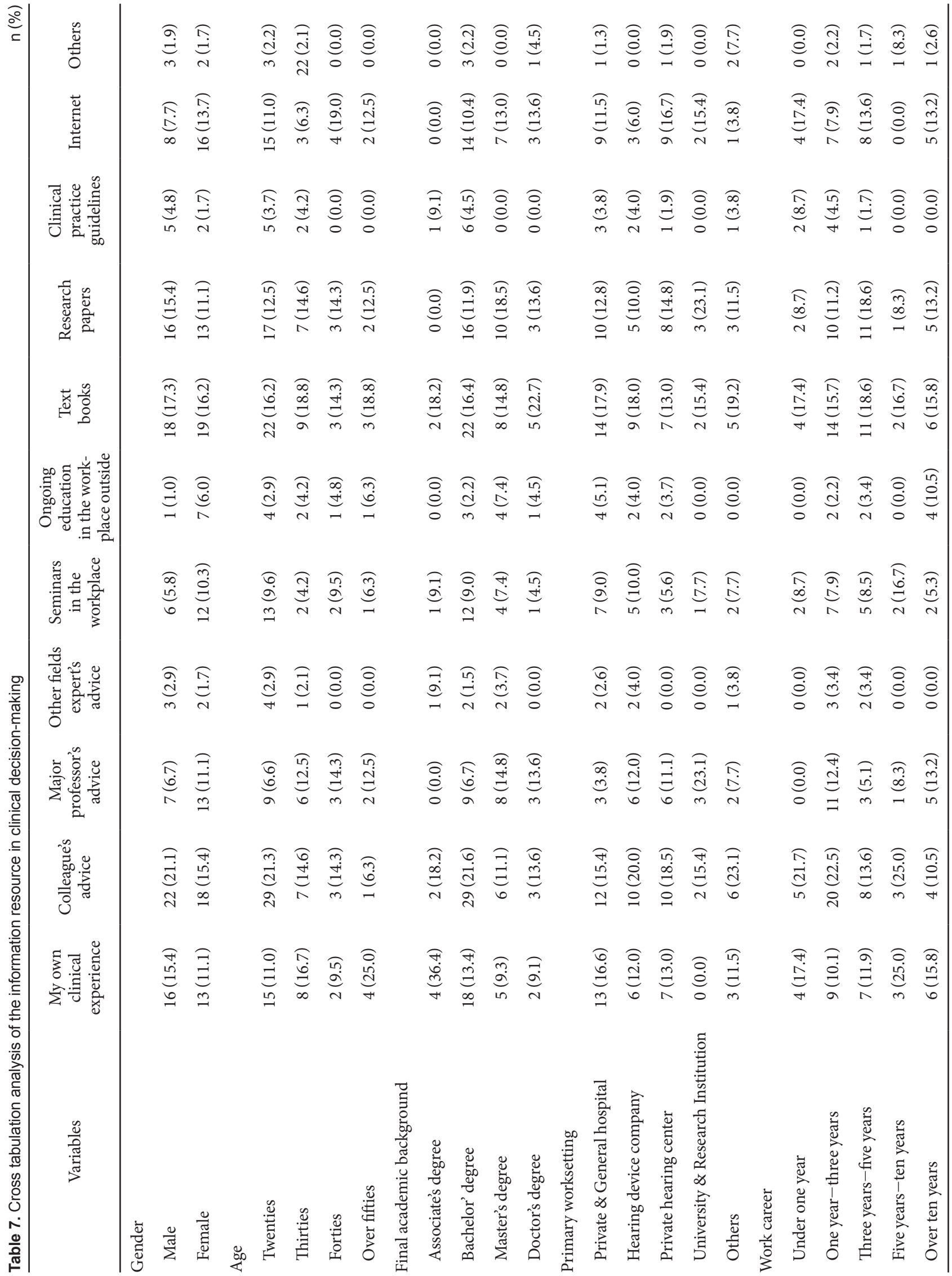


및 연구 논문(29명, $13.1 \%)$ 등의 방법 순으로 문제를 해결하는 것으로 나타났다(Figure 1).

이 결과를 연구 대상자의 일반적 특성인 성별, 연령대, 최종학 력, 근무경력 및 근무기관의 유형에 따라 교차 분석한 결과, 성 별에 따라 임상현장에서의 문제해결 방법으로 여성은 전공 선 후배들이나 동료의 조언(22명, $21.1 \%)$ 이 가장 높았지만, 남성은 전공 서적(19명, 16.2\%)이 가장 높게 나타났다. 연령대별로는 20 대는 전공 선후배들이나 동료의 조언(29명, 21.3\%), 30대는 전 공 서적(9명, $18.8 \%)$ 이 가장 높았던 반면에 40 대는 자신의 임상 적 경험이 가장 높게 나타났다(4명, 25\%). 그 외 자세한 내용은 Table 7과 같다.

\section{DISCUSSIONS}

본 연구는 국내 청능사들의 $\mathrm{EBP}$ 에 대한 인식 및 실행 수준 과 임상적 의사결정 시 이용하는 정보자원에 대해 고찰해봄으 로써 청각분야에서 $\mathrm{EBP}$ 에 대한 이해도를 향상시키고, 인식 변 화를 유도함으로써 추후 임상 및 재활 현장에서의 효과적인 적 용 방안을 모색하는 데 그 목적을 두었다.

우선 $\mathrm{EBP}$ 에 대한 청능사의 인식 수준정도는 $\mathrm{EBP}$ 에 대한 개념 이해정도와 일반적인 인식 수준의 두 가지 측면에서 분석 하였다. 연구 결과, 연구 대상자들의 $\mathrm{EBP}$ 에 대한 개념 이해정 도는 평균 2.13점으로 보통 이하의 수준이었다. 특히 연구 대상 자의 일반적 특성 중 약 $78.8 \%$ 정도가 $\mathrm{EBP}$ 에 대한 교육 경험 이 없는 것으로 나타나 국내 작업치료사들의 약 $75.6 \%$ 가 EBP 에 대한 교육 경험 없다고 조사한 Kim et al.(2012)의 연구와 거의 유사한 결과를 나타내어 비교적 낮게 측정된 $\mathrm{EBP}$ 에 대한 개념이해도와 관련 있을 것으로 추정된다. 임상 현장에서 $\mathrm{EBP}$ 의 적용 정도나 중요성에 대한 청능사의 일반적인 $\mathrm{EBP}$ 인식 수준은 평균 3.49점이었으며, 문항별로는 '청각학 분야의 연구 동향을 파악하는 것은 청능사로서의 중요한 직업적 책임이다' 문항이 4.04점으로 가장 높게 나타났고, 그 외 $\mathrm{EBP}$ 가 청각 임 상 분야에서 중요하고(3.66점), 임상현장에서의 $\mathrm{EBP}$ 가 청각적 중재나 재활의 효과를 향상시킬 수 있다며(3.64점), 긍정적으로 인식하는 것으로 나타났다. 반면에 청각학 관련 연구 결과의 부족으로 아직 $\mathrm{EBP}$ 사용이 제한적이라는 인식 역시 3.64점으 로 나타나 추후 이러한 $\mathrm{EBP}$ 방해 요인에 대한 철저한 분석이 필요할 것으로 생각된다. 본 연구 결과를 언어재활사의 $\mathrm{EBP}$ 인 식을 연구한 Yoon et al.(2014)의 결과와 비교해 보면 EBP가 언 어재활사의 직업적 의무 중 하나라고 인식하는 문항(4.05점)은 비슷하게 나타났지만, 전반적으로 청능사의 $\mathrm{EBP}$ 인식 수준 (3.49점)이 언어재활사의 $\mathrm{EBP}$ 인식 수준(3.98점)에 비해 다소 낮게 측정되었는데 이는 본 연구 대상자의 $67.5 \%$ 가 학사 출신
인 반면에 Yoon et al.(2014)의 연구에서는 77.8\%가 석사 이상 으로 연구 대상자의 구성 및 설문 문항의 차이에 따른 결과일 것으로 추측할 수 있다.

$\mathrm{EBP}$ 에 대한 청능사의 실행 수준정도는 평균 3.03점으로 $\mathrm{EBP}$ 에 대한 청능사의 인식 수준에 비해서 비교적 낮게 나타나 실제 임상 현장에서 적용하는 데 여러 가지 방해요인이 있을 것으로 추정된다. 각 문항별로는 '나는 정보검색, 색인사용, 다 운로드, 문서작성 등 컴퓨터를 잘 활용할 수 있다라는 문항이 3.46점으로 가장 높게 나타난 반면에 '나는 근무 시간 중 근거 기반실무에 참여할 시간이 있다(2.75점)'의 문항이 가장 낮게 나타났으며, 그 외 연구 관련 전문용어나 통계적 처리방법에 대 한 이해 정도(2.88점) 및 연구 활동(ex, 연구모임, 사례발표, 원 서강독 등)에 대한 참여 정도(2.89점) 역시 다른 문항에 비해 비교적 낮게 측정되었다. 이와 관련하여 Kwon(2006)의 연구결 과에서도 물리치료사의 $\mathrm{EBP}$ 적용에 가장 큰 방해요인이 $\mathrm{EBP}$ 를 적용할 시간의 부족으로 나타나 본 연구 결과와 일치하였 고, 그 외 선행연구에서도 $\mathrm{EBP}$ 적용 시간의 부족, 문헌검색 및 논문 해석 방법에 대한 지식부족, 근무 기관의 행정적 지원 부 족 등이 EBP 실행의 방해요인으로 확인되었다(Cho et al., 2011; Kim, 2010; Thompson et al., 2006).

연구 대상자의 특성에 따른 청능사의 EBP 인식 수준 비교 에서는 연령, 최종학력, 근무경력, 최근 2년간 학술대회 참석 여 부, 최근 6개월 동안 읽은 평균 논문 수 및 웹 기반 $\mathrm{DB}$ 활용 정 도에 따라 유의미한 차이가 있는 것으로 나타나 연령이나 최종 학력이 높고 10 년 이상의 근무경력을 가진 청능사일수록 EBP 에 대한 인식 수준이 높았다. 그리고 최근 2년간 학술대회에 참 석한 경험이 있으며 최근 6개월 동안 읽은 평균 논문 수가 4 5 편이고, 웹 기반 $\mathrm{DB}$ 를 매일 활용하는 청능사가 $\mathrm{EBP}$ 인식에 더 긍정적임을 알 수 있었다. 특히 50대 이상 연구 대상자의 EBP 인식 수준이 높은 이유는 최종학력이 모두 석사 및 박사 이상 이어서 연령이 높음에도 불구하고 $\mathrm{EBP}$ 에 대한 중요성을 더욱 긍정적으로 인식하는 것으로 생각되어 $\mathrm{EBP}$ 에 대한 인식은 다 양한 연구 경험과도 관련이 있을 것으로 생각된다. 연구 대상자 의 일반적 특성에 따른 청능사의 $\mathrm{EBP}$ 실행 수준 비교에서는 근무기관, 학회 회원 여부 및 $\mathrm{EBP}$ 교육 경험 여부를 제외한 모 든 변인에 따라 유의미한 차이가 있는 것으로 나타나 $\mathrm{EBP}$ 에 대한 인식 수준과 마찬가지로 40대의 최종학력이 높고 10년 이 상의 근무경력을 가진 청능사일수록 $\mathrm{EBP}$ 실행 수준이 높았고, 최근 2년간 학술대회에 참석한 경험이 있으며 최근 6개월 동안 읽은 평균 논문 수가 6편 이상이며 웹 기반 $\mathrm{DB}$ 를 매일 활용하 는 청능사가 $\mathrm{EBP}$ 실행 수준에서 높은 점수를 나타내었다.

$\mathrm{EBP}$ 인식 수준에 영향을 주는 요인을 확인하기 위하여 단 계별 다중선형 회귀분석을 실시한 결과 최종학력, 논문발표 경 
험 및 웹 기반 $\mathrm{DB}$ 활용 정도만이 예측 요인으로 나타나 교육 수준이 높고 논문발표 경험 및 웹 기반 $\mathrm{DB}$ 활용 정도가 높을 수록 $\mathrm{EBP}$ 인식을 잘 하는 것으로 생각할 수 있다. 또한 $\mathrm{EBP}$ 실행 수준에 영향을 주는 요인을 알아본 결과 최종학력, 웹 기 반 $\mathrm{DB}$ 활용 정도, 학회 회원 여부, 학회 참석 여부, 근무경력, 근무기관이 예측 요인으로 확인되었다. 언어재활사를 대상으로 한 Choi \& Hwang(2015)과 Zipoli \& Kennedy(2005)의 연구에 서는 임상실습 기간 중 연구에 대한 노출 정도와 평가 및 중재 관련 읽은 논문 수의 두 변인이 근거기반실무에 대한 인식 및 태도를 예측할 수 있는 의미 있는 요인으로 확인된 바 있다. 또 한 간호사들의 $\mathrm{EBP}$ 실행에 영향을 주는 요인에 대한 Gerrish et al.(2008)과 Lim et al.(2011)의 연구에서는 근무경력, 직위, 연령 및 교육수준이 유의한 요인으로 측정되어 연령이 많을수 록, $\mathrm{EBP}$ 에 대해 들어본 경험이 있을수록 그리고 교육수준이 높을수록 $\mathrm{EBP}$ 에 대한 인식 및 실행 수준이 높게 나타났다. 이 러한 결과는 본 연구와 선행 연구들 간에 사용한 변인의 차이 로 인해 예측 요인이 정확히 일치하지는 않지만 교육 수준, 연구 에 대한 노출 및 논문에 대한 경험 등이 EBP 인식 및 실행에 유 의한 영향을 주는 것으로 생각할 수 있다. 이와 같은 $\mathrm{EBP}$ 인식 및 실행 수준에 영향을 미치는 개인의 일반적 특성 외에도 EBP 에 대한 실행에 대한 자기효능, 가치에 대한 신념, 태도, 비판적 사고 등의 내면적 요인들도 영향을 주는 알려져 있다(Park, 2013). 다만 본 연구의 경우 EBP 인식 및 실행 수준에 영향을 미치는 요인을 확인하기 위한 회귀분석 결과, 모형의 결정력을 설명하는 결정계수가 각각 0.076 과 0.236 으로 측정되어 예측력 이 매우 낮게 나타났으므로 연구 결과에 대한 해석 시 유의할 필요가 있다.

임상현장에서 임상적 의사결정을 내리거나 불확실성을 해결 하기 위해 적절한 정보자원을 선택하고 이용하는 것은 매우 중 요한 절차이다(Lee, 2015). 본 연구에서 청능사들이 임상적 의 사결정 시 주로 이용하는 정보자원을 분석한 결과, 전공 선후 배들이나 동료의 조언이 $18.1 \%$ 로 가장 많았으며 그 다음이 전 공 관련 서적(16.7\%)과 자신의 임상적 경험(13.1\%) 및 연구 논 문(13.1\%) 순이었다. 이와 관련하여 전공 선후배들 및 동료의 조언이나 자신의 임상적 경험을 전통적인 정보자원으로 분류 한 Zipoli \& Kennedy(2005)의 연구에서도 임상가들이 근거기 반 정보자원보다는 전통적인 정보자원에 더 의존적인 것으로 나타나 본 연구의 결과와 유사하게 나타났다. 연구 대상자의 일 반적 특성 따른 임상적 의사결정 시 이용하는 정보자원에 대한 교차분석 결과, 특히 여성은 전공 선후배들이나 동료의 조언 (21.1\%)과 같은 전통적인 정보자원을, 남성은 전공 서적(16.2\%) 을 가장 많이 이용하는 것으로 나타났다. 연령대별로는 20 대와 40 대에서 전공 선후배들이나 동료의 조언이나 자신의 임상적
경험에 가장 많이 의존하는 것으로 나타났는데, 이러한 결과는 근무경력이 비교적 짧은 20대의 경우 임상적 경험이 많은 동료 들의 의견에 의존적인 경향이 많은 반면에 근무경력이 상대적 으로 긴 40대의 경우 자신의 축적된 임상적 경험에 대한 자신 감이 반영된 결과로 근무경력과 관련이 있음을 추측할 수 있다.

앞에서 살펴보았듯이 의학 및 간호 분야 외에도 최근에는 재 활 관련 분야에서도 $\mathrm{EBP}$ 에 대한 인식 및 실행 수준, 정보자원 이용 및 방해 요인 등을 분석하여 개선방향을 모색하고 그 결과 를 실제 임상 분야에 적용하고자 노력하고 있으며(Park, 2005), $\mathrm{EBP}$ 에 대한 중요성을 인식하고 활용하고자 하는 연구도 활발 히 진행되고 있는데 $\mathrm{EBP}$ 를 임상분야에서 효과적으로 실행하 고 적용하기 위해서는 다양한 논문이나 정보를 검색, 분석(비 판) 및 통합할 수 있는 정보활용능력과 같은 개인차원의 요인뿐 만 아니라 근무기관의 유형과 수용적 문화 및 직원에 대한 지원 등과 같은 조직차원의 요인이 모두 적절하게 고려되어야 한다 (Park, 2013). 즉 $\mathrm{EBP}$ 를 임상 실무에 확산 및 적용시키기 위해 서는 $\mathrm{EBP}$ 관련 지식과 기술 향상을 위한 교육의 기회를 제공 하고 최신 연구결과 및 연구동향을 소개하여 개인차원의 인식 변화를 유도하고 이와 함께 EBP 실행에 대한 근무기관의 재정 및 행정적 지원 강화를 통한 조직차원의 촉진노력도 필요하다 (Hwang, 2013). 특히 임상현장에서 과중한 업무 부담으로 인 해 근무시간 동안 문헌 탐색할 시간과 지속적인 교육과정에 참 여할 시간이 부족한 점이 $\mathrm{EBP}$ 실행에 있어서 주된 방해요인으 로 언급된 바 있으므로 조직차원에서의 지원노력이 매우 중요 하다(Kim et al., 2012). 특히 청각분야의 경우 근거자원으로 활용할 수 있는 국내 논문이 타 학문에 비해 부족한 실정이므 로 관련 학회나 협회를 중심으로 연구 성과물을 공유하고 소 개할 수 있는 연구모임이나 네트워크를 활성화시키고, $\mathrm{EBP}$ 의 중요성을 청각관련 기관에 적극적으로 홍보하는 학회 및 협회 차원의 노력 역시 $\mathrm{EBP}$ 실행의 중요한 기반이 될 수 있을 것으 로 생각된다.

임상현장에서의 성공적인 $\mathrm{EBP}$ 실행을 위해서는 먼저 $\mathrm{EBP}$ 개념 이해를 위한 교육 프로그램 개발이 선행되어야 하는데, $\mathrm{EBP}$ 교육내용은 임상질문 작성, 근거검색, 체계적 고찰, 비평적 평가 등으로 구성하거나, $\mathrm{EBP}$ 기본단계인 임상질문 작성, 근거 검색, 비평적 평가, 실무 적용 및 평가과정을 활용할 수 있다 (Park et al., 2009; Sim, 2014). EBP 교육프로그램의 개발이 활 발히 진행되고 있는 간호분야의 경우 간호대생과 임상 간호사 를 대상으로 2 7일 과정의 워크숍이나 1회 혹은 수회기 동안 강의, 실습, 토론 그룹, 멘토 프로젝트의 혼합 형태로 $\mathrm{EBP}$ 교육 프로그램을 진행하기도 한다. 프로그램의 내용은 임상질문 개 발을 위한 지도, 근거검색 능력 구축, 비평적 평가 능력 학습 등 을 강의와 실습을 통해 집중 교육하거나, 실무에 직접 적용 후 
그 결과를 평가하는 것이며, $\mathrm{EBP}$ 교육프로그램의 적용으로 인 해 $\mathrm{EBP}$ 에 대한 지식/기술, 태도, 실행 및 정보활용능력 등 다양 한 측면에서 유의한 향상을 나타내고 있었다(Cho et al., 2013; Park, 2013). 하지만 의학이나 간호분야를 제외하고는 EBP 교 육프로그램 개발이 거의 이루어지고 있지 않는 실정으로 추후 선행 연구에 대한 고찰과 분석을 통해 청각분야에 적합한 교육 프로그램의 개발이 필요할 것으로 생각된다.

본 연구는 청능사를 대상으로 $\mathrm{EBP}$ 에 대한 인식 및 실행 수 준을 확인하고 영향을 주는 요인을 분석하였으며, 임상적 의사 결정 시 이용하는 정보자원에 대해서도 살펴보았다는 점에서 연구의 의의를 찾을 수 있다. 하지만 본 연구의 제한점으로 첫 째, 연구 대상자의 70\%가 20 30대였고 5년 미만의 경력을 가 진 대상자도 $76.3 \%$ 가 포함되어 응답자들의 일반적 특성이 고 르게 분포되어 있지 않아 연구 결과가 특정 연령군 및 경력을 가진 청능사만을 대표하는 성격을 나타낼 수 있으므로 이를 전 체 청능사들의 결과로 일반화시켜 해석하기에는 무리가 따른 다. 즉, 40 50대 이상의 근무경력이 많은 청능사들에 대한 결 과는 본 연구결과와는 다르게 도출될 수 있으므로 추후 40 50 대 고연령층이 다수 포함된 다양한 연령대와 근무경력이 많 은 청능사들을 대상으로 한 비교연구가 시행된다면, 더 의의가 있을 것으로 생각된다. 둘째, 본 연구에서는 $\mathrm{EBP}$ 적용에 대한 방해요인을 자세히 분석이 하지 않은 한계점이 있으므로 $\mathrm{EBP}$ 방해요인을 측정할 수 있는 설문 문항에 대한 보완과 더불어 체계적인 분석을 통해 청각분야에서의 실질적인 적용 방안을 모색해야 할 것이다. 이러한 제한점에도 불구하고 본 연구를 통 해 청능사들이 $\mathrm{EBP}$ 에 대해 긍정적으로 인식하고 있음을 확인 하였으며, 청능사가 보다 경쟁력 있는 전문가로서 임상 및 재활 분야의 질적인 향상을 도모하기 위해서는 학회, 세미나, 보수 교육 등을 통해서 $\mathrm{EBP}$ 에 대해 명확히 이해할 수 있는 교육 경 험의 기회를 우선적으로 제공해야 할 필요가 있고, 이와 더불 어 $\mathrm{EBP}$ 적용방법에 대한 교육이 지속적으로 이루어져야 할 것 으로 생각된다. 실제 외국의 경우 $\mathrm{EBP}$ 실행을 위한 교육 프로 그램을 정규교육 과정에 도입하여 긍정적인 결과를 도출하고 있 으며, 위에서도 언급한 바와 같이 국내에서도 의학이나 간호분 야의 경우 $\mathrm{EBP}$ 실행을 위한 교육프로그램을 개발하고 그 효과 를 검증하고자 하는 노력들이 이루어지고 있으므로 추후 청각 분야에서도 학술 논문을 평가할 수 있는 연구 방법론적 내용 을 반영한 ‘EBP 실행을 위한 교육프로그램’ 개발에 관한 지속 적인 연구가 필요할 것으로 생각된다.

중심 단어 : 청능사·근거기반실무·정보자원이용.

\section{REFERENCES}

American Seech-Language-Hearing Association (ASHA). (2005a). Evidencebased practice in communication disorders. Retrieved from http:// asha.org/policy/ps2005-00221.htm/.

American Seech-Language-Hearing Association (ASHA). (2005b). ASHA Evidence Maps. Retrieved from http://www.asha.org/Evidence-Maps/.

Cho, H. M. (2006). Medical information retrieval for evidence-based medicine. Journal of Korean Society of Quality Assurance in Health Care, 12(2), 17-25.

Cho, M. S., Cho, Y. A., Song, M. R., Kim, M. K., \& Cha, S. K. (2013). Development of a program to facilitate evidence-based practice based on the transtheoretical model. The Journal of Korean Academic Society of Adult Nursing, 25(2), 136-147.

Cho, M. S., Song, M. R., \& Cha, S. K. (2011). Nurses' perceptions regarding evidence-based practice facilitators in a tertiary hospital. Journal of Korean Academy of Fundamentals of Nursing, 18(3), 300-309.

Cho, S. J. (2014). A Review of evidence-based practice in the audiological field. Audiology, 10(3), 181-189.

Choi, S. Y. \& Hwang, S. S. (2015). Attitudes, utilization, and barriers regarding evidence-based practice among speech-language pathologists in Korea. Communication Sciences and Disorders, 20(1), 106-120.

Cook, D. J., Jaeschke, R., \& Guyatt, G. H. (1992). Critical appraisal of therapeutic interventions in the intensive care unit: Human monoclonal antibody treatment in sepsis. Journal of Intensive Care Medicine, $7(6), 275-282$

Cox, R. M. (2005). Evidence-based practice in provision of amplification. Journal of the American Academy of Audiology, 16(7), 419-438.

Dysart, A. M. \& Tomlin, G. S. (2002). Factors related to evidence-based practice among US occupational therapy clinicians. American Journal of Occupational Therapy, 56(3), 275-284.

Gerrish, K., Ashworth, P., Lacey, A., \& Bailey, J. (2008). Developing evidence-based practice: Experiences of senior and junior clinical nurses. Journal of Advanced Nursing, 62(1), 62-73.

Hickson, L., Laplante-Lévesque, A., \& Wong, L. (2013). Evidence-based practice in audiology: Rehabilitation options for adults with hearing impairment. American Journal of Audiology, 22(2), 329-331.

Hwang, J. I. (2013). Hospital nurses' uses of evidence, and barriers to and enablers of evidenced-based practice. Journal of Korean Academy of Nursing Administration, 19(2), 292-303.

Kang, D. H., Kim, J. K., \& Lee, J. E. (2007). Perception of Korean occupational therapists on evidence-based occupational therapy. Journal of Korean Society of Occupational Therapy, 15(1), 12-23.

Kim, J. R., Kim, S. H., \& Yang, N. Y. (2012). Evidence-based practice (EBP) among Korean occupational therapists: Use of resources, perceptions, and barriers. Therapeutic Science of Neurorehabilitation, 1(1), 41-53.

Kim, S. J. (2010). Impact of doctor's EBM perception on use of clinical practice guideline (unpublished master's thesis). Seoul National University, Seoul.

Kwon, M. J. (2006). A survey of evidence-based practice of physical therapist. The Journal of Korean Society of Physical Therapy, 18(3), 23-36.

Lee, H. J. (2015). Relationships among information resources use, information literacy competency and evidence-based practice in university hospital (unpublished master's thesis). Gyeongsang University, Jinju.

Lee, Y. J. (2012). Development of a competency model for evidence based nursing practice (unpublished doctor's thesis). Yonsei University, Seoul.

Lee, Y. M. (2001). A case of educational use for evidence-based medicine. Korean Medical Education Review, 3(1), 37-45.

Leigh, J., Dettman, S., Dowell, R., \& Sarant, J. (2011). Evidence-based approach for making cochlear implant recommendations for infants with residual hearing. Ear and Hearing, 32(3), 313-322.

Lim, K. C., Park, K. O., Kwon, J. S., Jeong, J. S., Choe, M. A., Kim, J. H., et al. (2011). Registered nurses' knowledge, attitudes, and practice about evidence-based practice at general hospitals in Korea. Journal of Ko- 
rean Clinical Nursing Research, 17(3), 375-387.

Park, H. Y. (2013). Structural model of evidence-based practice implementation among clinical nurses (unpublished doctor's thesis). Chonnam University, Gwangju.

Park, J. H., Yoon, T. Y., \& Ko, J. K (2009). Development and validation of a questionnaire to evaluate medical students' evidence-based medicine competencies. Korean Journal of Medical Education, 21(3), 259-267.

Park, J. Y. (2012). Study on introducing of evidence-based medicine (EBM) information services: Based on the clinical residents' information seeking behavior and the perception of EBM (unpublished master's thesis). Myongji University, Seoul.

Park, M. (2013). Implementation of evidence based nursing education into nursing management clinical practicum: Outcome evaluation and diffusion strategies. Journal of Korean Academy of Nursing Administration, 19(1), 39-47.

Park, M. S. (2008). Evidence-based medicine. Neonatal Medicine, 15(1), $1-5$.

Park, M. W. (2005). Theory : Practical examples of applying evidence based nursing practice. Journal of Nursing Query, 13(2), 60-76.
Sackett, D. L., Rosenberg, W. M., Gray, J. M., Haynes, R. B., \& Richardson, W. S. (1996). Evidence based medicine: What it is and what it isn't. British Medical Journal, 312(7023), 71-72.

Sim, J. Y. (2014). The effect and education program development for evidence-based practice implementation of clinical nurse (unpublished doctor's thesis). Chonnam University, Gwangju.

Thomas, P. A. \& Cofrancesco, J. (2001). Introduction of evidence-based medicine into an ambulatory clinical clerkship. Journal of General Internal Medicine, 16(4), 244-249.

Thompson, D. R., Chau, J. P., \& Lopez, V. (2006). Barriers to, and facilitators of, research utilisation: A survey of Hong Kong registered nurses. International Journal of Evidence-Based Healthcare, 4(2), 77-82.

Yoon, J. H., Kim, S. W., \& Kim, J. W. (2014). An investigation into the actual condition and perception on evidence-based practice in Korean speech language pathologists. Journal of Rehabilitation Research, 18(18), 241261.

Zipoli, R. P. \& Kennedy, M. (2005). Evidence-based practice among speechlanguage pathologists attitudes, utilization, and barriers. American Journal of Speech-Language Pathology, 14(3), 208-220. 


\section{APPENDIX}

A Study on Audiologist's Perception and Performance Levels for the Evidence-Based Practice () 해당되는 곳에 표시해 주십시오.

1. 성별은 어떻게 되십니까? : (1) 남 (2) 여

2. 연령대는 어떻게 되십니까? : (1) 20 대 (2) 30 대 (3) 40 대 (4) 50 대 이상

3. 최종학력은 어떻게 되십니까? : (1) 전문학사 (2) 학사 (3) 석사 (4) 박사

4. 근무 경력은 어떻게 되십니까? :
(1) 1 년 미만
(2) 1년 이상 3년 미만
(3) 3년 이상 5년 미만
(4) 5 년 이상 10년 미만
(5) 10년 이상

5. 근무하시는 기관은 어디입니까 ?
(1) 개인 및 종합병원
(2) 청각기기 회사
(3) 개인청각센터
(4) 대학 및 연구기관
(5) 기타 (

6. 청각학 관련 학회나 학술단체에 회원으로 소속되어 있습니까?

(1) 예

(2) 아니오

7. 최근 2년간 청각학 관련 기관, 협회, 학회 등의 학술대회에 참석한 적이 있습니까? (1) 예 (2) 아니오

8. 지난 6 개월 동안 읽은 평균 논문 수는 어느 정도입니까?
(1) 1 편 미만
(2) 1 편 정도
(3) 2 3편 정도
(4) 4 5편 정도
(5) 6편 이상

9. RISS4U(학술연구정보서비스)/DBpia(누리미디어)/PubMed or MEDLINE 등과 같은 국내외 웹 기반 데이터베이스를 얼마나 자주 활용하십니까?
(1) 거의 활용하지 않음
(2) 1 년에 몇 번 정도
(3) 월 1 회 정도
(4) 주 1 회 정도
(5) 매일

10. 학교나 관련 기관에서 증거기반실무(EBP)에 관한 교육을 받은 적이 있습니까?

(1) 예

(2) 아니오 
1. 근거기반실무(EBP)라는 개념을 어느 정도 알고 계십니까?
(1) 전혀 모른다.
(2) 약간 알고 있다.
(3) 보통 정도 알고 있다.
(4) 어느 정도 잘 알고 있다.
(5) 매우 잘 알고 있다.

2. 근거기반실무(EBP)는 청각 임상분야에서 중요하다고 생각한다.
(1) 전혀 동의하지 않는다.
(2) 별로 동의하지 않는다.
(3) 보통이다.
(4) 약간 동의한다.
(5) 매우 동의한다.

3. 근거기반실무(EBP)는 임상에서 과학적 근거가 아닌 요소를 제거할 수 있다.
(1) 전혀 동의하지 않는다.
(2) 별로 동의하지 않는다.
(3) 보통이다.
(4) 약간 동의한다.
(5) 매우 동의한다.

4. 근거기반실무(EBP)는 청각적 중재나 재활의 효과를 향상시킨다.
(1) 전혀 동의하지 않는다.
(2) 별로 동의하지 않는다.
(3) 보통이다.
(4) 약간 동의한다.
(5) 매우 동의한다.

5. 임상적 판단을 할 때는 근거기반실무(EBP)를 적용해야 한다.
(1) 전혀 동의하지 않는다.
(2) 별로 동의하지 않는다.
(3) 보통이다.
(4) 약간 동의한다.
(5) 매우 동의한다.

6. 근거기반실무(EBP)는 이상적이지만, 매일의 임상현장에서 적용하기가 쉽지 않다.
(1) 전혀 동의하지 않는다.
(2) 별로 동의하지 않는다.
(3) 보통이다.
(4) 약간 동의한다.
(5) 매우 동의한다.

7. 청각학 분야의 연구동향을 파악하는 것은 청능사로서의 중요한 직업적 책임이다.
(1) 전혀 동의하지 않는다.
(2) 별로 동의하지 않는다.
(3) 보통이다.
(4) 약간 동의한다.
(5) 매우 동의한다.

8. 청각학 관련 연구결과가 아직 부족한 실정이기 때문에 근거기반실무(EBP)의 사용이 제한적이다.
(1) 전혀 동의하지 않는다.
(2) 별로 동의하지 않는다.
(3) 보통이다.
(4) 약간 동의한다.
(5) 매우 동의한다.

9. 근거기반실무(EBP)에 대한 특강이나 강좌가 개설된다면, 참여할 의사가 있다.
(1) 전혀 동의하지 않는다.
(2) 별로 동의하지 않는다.
(3) 보통이다.
(4) 약간 동의한다.
(5) 매우 동의한다. 


\section{II. 근거기반실무에 대한 실행 수준}

1. 나는 근거기반실무(EBP)를 위해 정보검색, 색인사용, 다운로드, 문서작성 등 컴퓨터를 잘 활용할 수 있다.
(1) 매우 그렇지 않다.
(2) 그렇지 않다.
(3) 보통이다.
(4) 그렇다.
(5) 매우 그렇다.

2. 나는 논문이나 연구 결과를 검색할 수 있는 데이터베이스(Pubmed, Medline, RISS4U)를 잘 알고 있다.
(1) 매우 그렇지 않다.
(2) 그렇지 않다.
(3) 보통이다.
(4) 그렇다.
(5) 매우 그렇다.

3. 나는 연구 관련 전문용어나 통계적 처리방법에 대해서 잘 알고 있다.
(1) 매우 그렇지 않다.
(2) 그렇지 않다.
(3) 보통이다.
(4) 그렇다.
(5) 매우 그렇다.

4. 나는 국내외 연구 논문을 읽고, 해석하여 평가할 수 있다.
(1) 매우 그렇지 않다.
(2) 그렇지 않다.
(3) 보통이다.
(4) 그렇다.
(5) 매우 그렇다.

5. 나는 현재 임상 현장에서 연구결과나 문헌을 참고해서 문제점을 해결하고 있다.
(1) 매우 그렇지 않다.
(2) 그렇지 않다.
(3) 보통이다.
(4) 그렇다.
(5) 매우 그렇다.

6. 내가 속한 기관에서 시행하는 연구(ex, 연구모임, 사례발표, 원서강독 등)에 참여하고 있다.
(1) 매우 그렇지 않다.
(2) 그렇지 않다.
(3) 보통이다.
(4) 그렇다.
(5) 매우 그렇다.

7. 나는 근무 시간 중 근거기반실무(EBP)에 참여할 시간이 있다.
(1) 매우 그렇지 않다.
(2) 그렇지 않다.
(3) 보통이다.
(4) 그렇다.
(5) 매우 그렇다.

\section{III. 임상적 의사결정 시 이용하는 정보자원}

임상 현장에서 의문점이나 어려움을 해결할 때 어떠한 경로를 이용했는지, 모두 선택해 주십시오.

- 나 자신의 임상적 경험을 바탕으로 해결책을 찾음

- 전공 선후배들이나 동료의 의견을 구함

- 전공 교수에게 상담을 구함

- 청각학 전공이 아닌 전문가의 의견을 구함

- 직장 내의 세미나, 연구, 워크솝 등을 통해서 해결책을 찾음

- 직장 밖에서 받은 지속적 교육을 통해서 해결책을 찾음

- 전공 서적을 참고함

- 연구 논문을 참고함 